\title{
The information content of the term structure of interest rates about future inflation - an illustration of the importance of accounting for a time-varying real interest rate and inflation risk premium*
}

\author{
Christian Mose Nielsen ${ }^{\dagger}$ \\ Department of Economics, Politics \\ and Public Administration \\ Aalborg University \\ Fibigerstræde 3 \\ 9220 Aalborg $\varnothing$ \\ Denmark
}

February 14, 2005

\begin{abstract}
During the past fifteen years a large number of studies have used the approach suggested by Mishkin $(1990 a, 1990 b)$ to examine the information content of the term structure of interest rates about future inflation. The empirical results of these studies are, however, very mixed and often not supportive of the Mishkin model. In addition, many results indicate that the term structure of interest rates only contains very limited information about future inflation. In this paper an extension of the Mishkin model allowing for time-varying real interest rates and inflation risk premiums is suggested and tested on monthly UK data from 1983:1 to 2004:10. The empirical results show that while the standard Mishkin model indicates that the term structure of interest rates contains very limited information about future inflation, the extended Mishkin model indicates the contrary, i.e. the term structure of interest rates contains much information about future inflation when account is taken for a time-varying slope of the term structure of real interest rates and inflation risk premiums. In addition, for the pre-inflation targeting period in the UK, the empirical results provide strong support for the extended Mishkin model when the slope along the entire term structure is used as an indicator of expected inflation.
\end{abstract}

${ }^{*}$ Comments to this draft are welcome.

†E-mail: chrmose@socsci.aau.dk. 


\section{Introduction}

Fifteen years ago Mishkin $(1990 a, 1990 b)$ published two articles on the information content of the term structure of interest rates about future inflation. Since then a number of authors have examined the information content of the term structure of interest rates about future inflation - see e.g. Browne \& Manasse (1990), Mishkin (1991), Jorion \& Mishkin (1991), Koedijk \& Kool (1995), Day \& Lange (1997) and Schich (2000). ${ }^{1}$ The empirical results of these studies are, however, very mixed and often not supportive of the Mishkin model. In addition, many results indicate that the term structure of interest rates only contains very limited information about future inflation. A common criticism and a possible explanation for these results is that the Fisher equation used to derive the Mishkin model is misspecified in the sense that it omits an inflation risk premium and that the real interest rate is time-varying. ${ }^{2}$ In this paper a simple approximation to the omitted time-varying real interest rate and the inflation risk premium is suggested, and the resulting extended Mishkin model which allows for a time-varying slope of the term structure of expected real interest rates and an inflation risk premium is tested using monthly UK data from 1983:1 to 2004:10. The empirical results show that while the standard Mishkin model indicates that the term structure of interest rates contains very limited information about future inflation, the extended Mishkin model indicates the contrary, i.e. the term structure of interest rates contains much information about future inflation when account is taken for a time-varying slope of the term structure of expected real interest rates and inflation risk premiums. In addition, the results for the pre-inflation targeting period 1983:1 to 1992:9 provide strong support for the extended Mishkin model when the slope along the entire term structure of interest rates is used as an indicator of future inflation.

The outline of the paper is as follows. In Section 2 the Mishkin model is presented and the extended Mishkin model is derived. Section 3 presents the data used in the paper. Section 4 presents the empirical results and Section 5 contains some concluding remarks.

\section{The Mishkin model and an extension}

The standard Fisher equation decomposes the $n$-period nominal interest rate, $i_{n, t}$, into the sum of the expected $n$-period real interest rate between time $t$ and $t+n, E_{t}\left[r r_{n, t+n}\right]$, and the expected inflation rate between time $t$ and $t+n$, $E_{t}\left[\pi_{n, t+n}\right]$ :

$$
i_{n, t}=E_{t}\left[r r_{n, t+n}\right]+E_{t}\left[\pi_{n, t+n}\right]
$$

\footnotetext{
${ }^{1}$ Other authors have used approaches similar to the Mishkin approach - see e.g. Fama (1990), Frankel \& Lown (1994) and Breedon \& Chadha (1997).

${ }^{2}$ See e.g. Benninga \& Protopapadakis (1983) and Evans \& Wachtel (1992) for a discussion of the inflation risk premium in the Fisher equation.
} 
The Mishkin model is the difference between the $m$ and $n$-period versions of the standard Fisher equation (1) together with the assumptions of a constant slope of the term structure of expected real interest rates and rational expectations. The latter assumption is used to write the realized inflation, $\pi_{n, t+n}$, as the sum of expected inflation, $E_{t}\left[\pi_{n, t+n}\right]$, and a rational expectation error, $\varepsilon_{n, t+n}$, which is uncorrelated with all time $t$ information. The Mishkin model is thus stated as:

$$
\pi_{m, t+m}-\pi_{n, t+n}=\alpha_{m, n}+\beta_{m, n}\left(i_{m, t}-i_{n, t}\right)+\eta_{m, n, t+m}
$$

where $m>n$ and:

$$
\begin{array}{rll}
\alpha_{m, n} & =-\left(\overline{r r_{m, t+m}-r r_{n, t+n}}\right) \\
\beta_{m, n} & =1 \\
\eta_{m, n, t+m} & =\varepsilon_{m, t+m}-\varepsilon_{n, t+n} & \\
\varepsilon_{j, t+j} & =\pi_{j, t+j}-E_{t}\left[\pi_{j, t+j}\right] \quad \text { for } j=m, n
\end{array}
$$

Due to the assumption of rational expectations, the error term is uncorrelated with all time $t$ information and OLS thus yields consistent estimates of $\alpha_{m, n}$ and $\beta_{m, n}$. Because of the multiperiod setup, the error term will follow an $\mathrm{MA}(m-1)$ process and inference based on normal OLS standard errors is not valid. However, estimating robust standard errors using e.g. the Newey \& West (1987) method allows hypotheses about the coefficients $\alpha_{m, n}$ and $\beta_{m, n}$ to be tested. Following Mishkin $(1990 a, 1990 b)$, two hypothesis are typically tested: 1) $\beta_{m, n}=1$, i.e. the hypothesis that the Mishkin model holds and 2) $\beta_{m, n}=0$, i.e. the hypothesis that the term structure of interest rates contains no information about future inflation. In this paper the Mishkin model is, however, only said to be supported by the data if the null hypothesis $\beta_{m, n}=0$ is rejected and the null hypothesis $\beta_{m, n}=1$ is not rejected.

Many studies using the Mishkin model find that it is rejected by the data. Possible solutions typically discussed are the possibility of a time-varying slope of the term structure of expected real interest rates and/or a time-varying inflation risk premium. If the slope of the term structure of expected real interest rates is not constant and/or an inflation risk premium has to be included in the Fisher equation, the Mishkin model in (2) omits relevant variables and OLS will produce inconsistent estimates of the $\alpha_{m, n}$ and $\beta_{m, n}$ parameters. In this paper an extended Mishkin model which allows for a time-varying slope of the term structure of expected real interest rates and a time-varying inflation risk premium is derived and examined empirically. The extended Mishkin model is derived from the Fisher equation with a time-varying inflation risk premium:

$$
i_{n, t}=E_{t}\left[r r_{n, t+n}\right]+E_{t}\left[\pi_{n, t+n}\right]+r p_{n, t}
$$

where $r p_{n, t}$ is the $n$-period inflation risk premium. Subtracting the $n$-period version of equation (3) from the corresponding $m$-period version and using the assumption of rational expectations yield the following extended version of the 
Mishkin model:

$$
\begin{aligned}
\pi_{m, t+m}-\pi_{n, t+n}= & \alpha_{m, n}+\beta_{m, n}\left(i_{m, t}-i_{n, t}\right) \\
& +\gamma_{m, n}\left(E_{t}\left[r r_{m, t+m}+r p_{m, t}\right]-E_{t}\left[r r_{n, t+n}+r p_{n, t}\right]\right) \\
& +\eta_{m, n, t+m}
\end{aligned}
$$

where

$$
\begin{aligned}
\alpha_{m, n} & =0 \\
\beta_{m, n} & =1 \\
\gamma_{m, n} & =-1 \\
\eta_{m, n, t+m} & =\varepsilon_{m, t+m}-\varepsilon_{n, t+n} \\
\varepsilon_{j, t+j} & =\pi_{j, t+j}-E_{t}\left[\pi_{j, t+j}\right] \quad \text { for } j=m, n
\end{aligned}
$$

The problem with testing equation (4) is that the expected real interest rate and risk premium term, $E_{t}\left[r_{m, t+m}+r p_{m, t}\right]-E_{t}\left[r_{n, t+n}+r p_{n, t}\right]$, is unobservable. A similar problem is encountered when the expectations hypothesis of the term structure of interest rates is tested. The expectations hypothesis states that long-term interest rates equal the average of current and expected future short-term interest rates over the life of the long-term bonds plus a possibly time-varying term premium. The term premium is, however, unobservable and therefore needs to be modelled. In a study examining the expectations hypothesis, Tzavalis \& Wickens (1997) propose a very simple model of the unobservable term premium. Their method builds on the findings by Heston (1992), who shows that within the Cox, Ingersoll \& Ross (1985) model of the term structure of interest rates, the unobservable term premium has a single-factor representation. Tzavalis \& Wickens (1997) use this finding to model the $m$-period term premium as a linear function of the $n$-period term premium. Knowledge of one term premium thus gives an approximation to the other term premiums. In their estimations, Tzavalis \& Wickens (1997) replace the unobserved term premium with an ex post term premium for another maturity. Using this setup, they find that they are able to reconcile the expectations hypothesis with the data. Based on these positive findings, it is interesting to examine if a similar simple single-factor representation of the sum of the expected real interest rate and the inflation risk premium in the Fisher equation may help reconcile the Mishkin model with the data. Denoting the sum of the expected $j$-period real interest rate and the $j$-period inflation risk premium by $E_{t}\left[\operatorname{rrrp}_{j, t+j}\right]$, i.e. $E_{t}\left[\operatorname{rrrp}_{j, t+j}\right] \equiv E_{t}\left[r r_{j, t+j}\right]+r p_{j, t}$, it is thus assumed that the sum of the expected $m$-period real interest rate and the $m$-period inflation risk premium is given by:

$$
E_{t}\left[r r r p_{m, t+m}\right]=\phi_{m, j} E_{t}\left[r r r p_{j, t+j}\right]
$$

The problem with the specification in equation (5) is that $E_{t}\left[r r r p_{j, t+j}\right]$ is unobservable. However, the Fisher equation and the assumption of rational ex- 
pectations imply that:

$$
\begin{aligned}
E_{t}\left[\operatorname{rrrp}_{j, t+j}\right] & =i_{j, t}-E_{t}\left[\pi_{j, t+j}\right] \\
& =i_{j, t}-\pi_{j, t+j}+\varepsilon_{j, t+j} \\
& =r_{j, t+j}+\varepsilon_{j, t+j}
\end{aligned}
$$

where:

$$
r_{j, t+j} \equiv i_{j, t}-\pi_{j, t+j}
$$

is the ex post $j$-period real interest rate implied by the $j$-period nominal interest rate and the realized $j$-period inflation rate. $E_{t}\left[r r r p_{j, t+j}\right]$ can thus be replaced by the ex post real $j$-period interest rate plus a rational expectation error, $\varepsilon_{j, t+j}$. In other words, using the Fisher equation and the assumption of rational expectations, it is possible to use the ex post real interest rate implied by the nominal interest rate and the future realized inflation rate as an approximation to the sum of the unobservable expected real interest rate and the inflation risk premium. In the case where real interest rates are constant, $E_{t}\left[r r r p_{j, t+j}\right]$ serves as an approximation to the unobservable inflation risk premium. In this case, it is thus assumed that the inflation risk premium has a single-factor representation. If uncertainty is increasing in maturity, it is expected that $\phi_{m, j}>1$ when $m>j$ and vice versa. The opposite holds if uncertainty is decreasing in maturity (e.g. if the economic agents believe in the central bank's long-run inflation target). Non-monotonic relationships are, of course, also possible. In the case with a constant inflation risk premium, $E_{t}\left[r r r p_{j, t+j}\right]$ serves as an approximation to the time $t$ unobservable expected $j$-period real interest rate. In this case the single-factor representation of $E_{t}\left[\operatorname{rrrp}_{j, t+j}\right]$ corresponds to the assumption that real interest rates have a single-factor representation. This assumption can be justified by referring to the class of affine single-factor models of the term structure of interest rates where interest rates of different maturities are given by a linear function of a single interest rate. Typically the short-term interest rate is used as the factor driving the term structure of interest rates but any interest rate can in principle be used as the factor driving the term structure of interest rates. ${ }^{3}$ In this case, $\phi_{m, j}$ therefore describes the shape of the term structure of expected real interest rates. In the following, however, $E_{t}\left[r r r p_{j, t+j}\right]$ is thought of as an approximation to the sum of a time-varying expected real interest rate and a time-varying inflation risk premium, and it is assumed that $E_{t}\left[\operatorname{rrrp}_{n, t+n}\right]$ has a single-factor representation. ${ }^{4}$

Using the single-factor representation of the sum of the expected real interest rate and the inflation risk premium in equation (5), and using $E_{t}\left[\operatorname{rrp}_{j, t+j}\right]=$

\footnotetext{
${ }^{3}$ See e.g. Cochrane (2001), chapter 19.

${ }^{4}$ Since ex post real interest rates are used as approximations to the sum of the expected real interest rate and the inflation risk premium in the extended Mishkin model, the sum of the expected real interest rate and the inflation risk premium can also be interpreted as a level variable indicating that the level of nominal interest and inflation rates influence the relationship between the slope of the term structure of interest rates and changes in future inflation.
} 
$r_{j, t+j}+\varepsilon_{j, t+j}$, it is thus possible to rewrite the extended Mishkin model (4) as:

$$
\pi_{m, t+m}-\pi_{n, t+n}=\alpha_{m, n}+\beta_{m, n}\left(i_{m, t}-i_{n, t}\right)+\gamma_{m, n} r_{j, t+j}+\eta_{m, n, t+m}
$$

where

$$
\begin{aligned}
\alpha_{m, n} & =0 \\
\beta_{m, n} & =1 \\
\gamma_{m, n} & =-\left(\phi_{m, j}-\phi_{n, j}\right) \\
\eta_{m, n, t+m} & =\varepsilon_{m, t+m}-\varepsilon_{n, t+n}-\left(\phi_{m, j}-\phi_{n, j}\right) \varepsilon_{j, t+j}
\end{aligned}
$$

In the following the extended Mishkin model (8) with $j=1$ and 3 will be examined. However, since $r_{j, t+j}$ by definition is correlated with $\varepsilon_{j, t+j}$ and thus also with $\eta_{m, n, t+m}$ whenever the term structure of "expected real interest rates plus the inflation risk premiums" is not flat, i.e. whenever $\phi_{m, j} \neq \phi_{n, j}$, it is necessary to estimate equation (8) using an instrumental variable method. In this chapter, the generalized instrumental variable (GIV) estimator suggested by Hansen \& Singleton (1982) is used. The standard errors are made robust to heteroskedasticity and autocorrelation of order $(m-1)$ using the Newey \& West (1987) estimator.

\section{Data}

This paper uses monthly UK interest rate and inflation rate data for the period 1983:1 to 2004:10. The inflation rates are calculated from monthly observations of the UK retail price index excluding mortgage interest payments (RPIX) for the period 1983:1 to 2004:10. The RPIX series is obtained from the Office for National Statistics and is seasonally adjusted using the X11 method in RATS. ${ }^{5}$ The inflation rates are calculated as continuously compounded inflation rates measured on an annual basis, i.e. as $\pi_{n, t}=\left(p l_{t}-p l_{t-n}\right) * 12 / n$ where $p l_{t}$ denotes the natural logaritm of the seasonally adjusted RPIX at time $t$.

The interest rates are obtained from two sources. Estimated zero-coupon interest rates with maturities 12, 24, 36 and 48 months are obtained from the Bank of England. ${ }^{6}$ These interest rates are available on a daily frequency and therefore have to be converted into a monthly frequency. Since the price index used refers to the second or third Tuesday in each month, ${ }^{7}$ mid-month observations of the interest rates are chosen. More specifically, the observations referring to the 15th of each month are chosen. If these observations are not available, the closest available observations to the 15 th are used instead. ${ }^{8}$ Since the Bank of

\footnotetext{
${ }^{5}$ The RPIX is seasonally adjusted since preliminary research indicated that especially the 1 and 3 month inflation rates would show clear seasonal patterns otherwise.

${ }^{6}$ See Bank of England (2002) and Anderson \& Sleath (2001) for a discussion of the estimation procedure used by the Bank of England.

${ }^{7}$ Office for National Statistics (1998), pp. 22-23.

${ }^{8}$ The only exception from this "rule" is October 1990 where the observations from the 12 th October are used instead of those from the 15th October. The reason for this is that the 12-month nominal interest rate is not available at the 15th October, and that the 12th October is the closest date where it is available.
} 
England does not report estimated 1 and 3-month zero-coupon interest rates before March 1997, the interest rate data used for these maturities are 1 and 3 -month UK Treasury Bill rates obtained from Datastream. ${ }^{9}$ As with the inflation rates all interest rates are expressed as continuously compounded rates (in decimal form) and measured on an annual basis. ${ }^{10}$ As is clear from figure 1 and table 1, a justification for using the 1 and 3-month Treasury Bill rates is that these rates are very close to the estimated 1 and 3-month zero-coupon interest rates over the 1997:3 to 2004:10 period.

Figure 1: Zero-coupon rates vs Treasury Bill rates
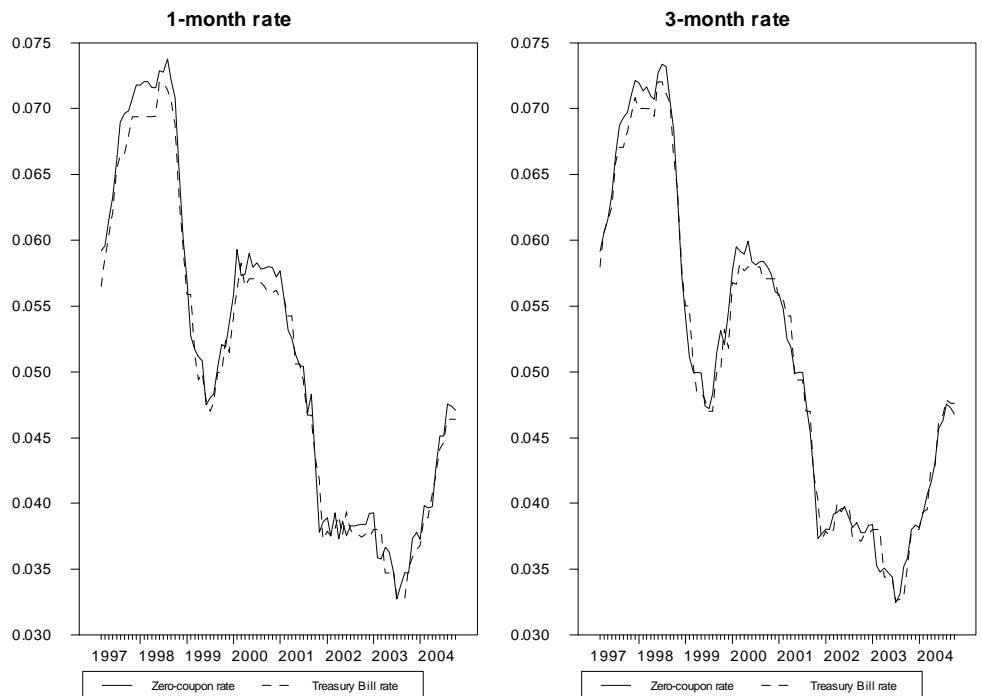

It is, of course, not possible to extrapolate the 1997:3 to 2004:10 behaviour to the 1983:1 to 1997:2 period, but based on the findings above, and since no immediate alternatives exist to the estimated 1 and 3-month zero-coupon rates before 1997:3, it is in the following assumed that the 1 and 3-month Treasury Bill rates can be used without affecting the main conclusions.

\footnotetext{
${ }^{9}$ The 1 and 3-month Treasury Bill rates have the Datastream codes LDNTB1M and LDNTB3M, respectively. These interest rates are available on a daily frequency. The monthly observations for the 1 and 3-month rates correspond to the same dates as the monthly observations for the estimated zero-coupon rates.

${ }^{10}$ The 1 and 3-month Treasury Bill rates are originally measured as effective interest rates in per cent and are thus converted to continuously compounded rates (on a decimal form) measured on an annual basis.
} 
Table 1: Descriptive statistics (1997:3 to 2004:10) for Bank of England estimated 1 and 3-month zero-coupon interest rates and 1 and 3-month Treasury Bill rates.

\begin{tabular}{lcccc} 
& \multicolumn{2}{c}{ 1-month rate } & \multicolumn{2}{c}{ 3-month rate } \\
& T-Bill & ZCR & T-Bill & ZCR \\
\hline mean & 0.05050 & 0.05136 & 0.05081 & 0.05117 \\
variance & 0.00014 & 0.00015 & 0.00014 & 0.00015 \\
skewness & 0.26481 & 0.30758 & 0.24592 & 0.30293 \\
kurtosis & -1.09730 & -1.09548 & -1.11264 & -1.09096 \\
correlation & \multicolumn{2}{c}{0.9952} & \multicolumn{2}{c}{0.9950} \\
\hline
\end{tabular}

T-Bill refer to Treasury Bill rates obtained from Datastream

ZCR refer to estimated zero-coupon interest rates obtained from Bank of England

The earliest starting date for the analysis is 1979:1 since estimated zerocoupon interest rates are not available before this date. Due to extreme behaviour of the 1 and 3-month inflation rates in the late 1970s and early 1980s, the analysis starts in 1983:1. The data used in the analysis are the $(3,1),(12,1)$, $(12,3),(24,1),(24,3),(36,1),(36,3),(48,1)$ and $(48,3)$ interest rate and inflation rate spreads and the 1 and 3 -month ex post real interest rates. The $(m, 1)$ inflation rate spreads and the 1-month real interest rate all contain an extreme outlier in 1990:4. The observation corresponding to 1990:4 is therefore replaced with the value found by linear interpolation between 1990:3 and 1990:5. ${ }^{11}$

Table 2: Number of lags (p) and t-statistic for ADF test with a constant

\begin{tabular}{llllllllc}
\hline & $\mathrm{p}$ & $\mathrm{t}-\mathrm{stat}$ & & $\mathrm{p}$ & $\mathrm{t}-$ stat & & $\mathrm{p}$ & $\mathrm{t}$-stat \\
$\mathrm{i}_{3}-\mathrm{i}_{1}$ & 1 & -5.1656 & $\pi_{3}-\pi_{1}$ & 1 & -15.7240 & $\mathrm{r}_{1}$ & 4 & -3.3041 \\
$\mathrm{i}_{12}-\mathrm{i}_{1}$ & 0 & -4.6119 & $\pi_{12}-\pi_{1}$ & 0 & -12.9584 & $\mathrm{r}_{3}$ & 3 & -2.9882 \\
$\mathrm{i}_{12}-\mathrm{i}_{3}$ & 0 & -4.4629 & $\pi_{12}-\pi_{3}$ & 11 & -5.8060 & & & \\
$\mathrm{i}_{24}-\mathrm{i}_{1}$ & 0 & -3.2465 & $\pi_{24}-\pi_{1}$ & 2 & -6.8373 & & & \\
$\mathrm{i}_{24}-\mathrm{i}_{3}$ & 0 & -3.0217 & $\pi_{24}-\pi_{3}$ & 3 & -3.7307 & & & \\
$\mathrm{i}_{36}-\mathrm{i}_{1}$ & 0 & -2.7421 & $\pi_{36}-\pi_{1}$ & 2 & -5.6896 & & & \\
$\mathrm{i}_{36}-\mathrm{i}_{3}$ & 0 & -2.5373 & $\pi_{36}-\pi_{3}$ & 3 & -3.1023 & & & \\
$\mathrm{i}_{48}-\mathrm{i}_{1}$ & 0 & -2.5018 & $\pi_{48}-\pi_{1}$ & 2 & -5.1187 & & & \\
$\mathrm{i}_{48}-\mathrm{i}_{3}$ & 0 & -2.3205 & $\pi_{48}-\pi_{3}$ & 3 & -2.5233 & & & \\
\hline
\end{tabular}

The $5 \%$ and $10 \%$ critical values are -2.86 and -2.57 , respectively.

Table 2 presents unit root tests of the data used. The order of integration of the variables used are determined using augmented Dickey-Fuller (ADF) tests with a constant and with lag length determined by adding lags until a Ljung-Box test statistic fails to reject the hypothesis of no serial correlation up until order 12. Using $10 \%$ asymptotic critical values the null hypothesis of non-stationary

\footnotetext{
${ }^{11}$ Preliminary research indicated that this has little influence on the main results in this paper.
} 
variables is rejected for all variables except $i_{48}-i_{1}, i_{36}-i_{3}, i_{48}-i_{3}$ and $\pi_{48}-\pi_{3}$. For $i_{48}-i_{1}, i_{36}-i_{3}$ and $\pi_{48}-\pi_{3}$ the null hypothesis of non-stationary variables is almost rejected at the $10 \%$ significance level. ${ }^{12}$ In addition, Phillips-Perron tests (not reported in the paper) with 4 or 12 lags reject the null hypothesis of non-stationary variables for all variables using $10 \%$ critical values. It thus seems reasonable to assume that all variables used in the analysis are stationary.

\section{Empirical results}

In the following, the results of OLS estimation of the standard Mishkin model (2) and GIV estimation of the extended Mishkin model (8) will be presented and discussed. ${ }^{13}$ The instruments used are a constant, $\left(i_{m, t}-i_{n, t}\right)$ and $r_{j, t}, \ldots, r_{j, t-5} \cdot{ }^{14}$ Empirical results are presented for the full sample 1983:1 to 2004:10, the period prior to the UK left the ERM, i.e. 1983:1 to 1992:9, and the inflation targeting period, i.e. $1992: 10$ to $2004: 10{ }^{15}$ In the following a $10 \%$ significance level will be used.

\subsection{The standard Mishkin model}

The results of OLS estimation of the standard Mishkin model are presented in table 3a-c. Interestingly, the Mishkin model is only supported for the $(48,3)$ spread in the 1983:1 to $1992: 9$ period, where the null hypothesis $\beta_{m, n}=0$ is rejected and the $\beta_{m, n}=1$ hypothesis is not rejected. Furthermore, as is clear from table $3 \mathrm{a}$, the null hypothesis $\beta_{m, n}=0$ is only rejected for the $(36,1)$ spread, i.e. the term structure of interest rates does not seem to contain much information about future inflation during the 1983:1 to 2004:10 period. In the two subperiods $1983: 1$ to $1992: 9$ and 1992:10 to 2004:10, the term structure of interest rates seems to contain some information about future inflation since

\footnotetext{
${ }^{12}$ Using the "finite sample" critical values tabulated by MacKinnon (1991) will make basically no difference due to the large number of observations. As discussed in Davidson \& MacKinnon (1993), p. 708, it may, however, in general be preferable to use asymptotic critical values.

${ }^{13}$ Hausman specification test have been calculated by regressing $r_{j, t+j}$ on the instruments using OLS. The predicted values from this regression are then used as an extra explanatory variable in the extended Mishkin model (8). This equation is then estimated using OLS and the significance of the predicted value of $r_{j, t+j}$ is tested using robust standard errors. The results of the Hausman specification test (not reported in the paper) indicate that the endogeneity of $r_{j, t+j}$ does not always have significant effect on the estimates. The GIV estimates are used since for some spreads and some time periods the endogeneity seems to have significant effect on the estimates, and since $r_{j, t+j}$ should be correlated with $\eta_{m, n, t+m}$ whenever the term structure of "expected real interest rates plus the inflation risk premiums" is not flat.

${ }^{14} \mathrm{~W}$ ith the exception of the $(48, \mathrm{n})$ spreads in the case with the $r_{3, t+j}$ approximation in the 1992:10 to 2004:10 period, a $J$-test for overidentifying restrictions (not reported in the paper) cannot reject the null hypothesis of "valid" instruments.

${ }^{15}$ Note that the actual starting date in the regressions are 1983:9 and 1993:6 since the use of $r_{3, t-5}$ as an instrument requires the use of $i_{3, t-8}$ and $\pi_{3, t-5}$. The results with and without different approximations to the slope of the term structure of expected real interest rates and inflation risk premiums can thus be directly compared.
} 
Table 3a: The Mishkin model 1983:1 to 2004:10

\begin{tabular}{ccccccc}
\hline & & \multicolumn{5}{c}{$\mathrm{p}$-values for } \\
$(\mathrm{m}, \mathrm{n})$ & $\alpha_{\mathrm{m}, \mathrm{n}}$ & $\beta_{\mathrm{m}, \mathrm{n}}$ & $\mathrm{s}\left(\beta_{\mathrm{m}, \mathrm{n}}\right)^{\mathrm{a}}$ & $\beta_{\mathrm{m}, \mathrm{n}}=0$ & $\beta_{\mathrm{m}, \mathrm{n}}=1$ & Adj. $\mathrm{R}^{2}$ \\
$(3,1)$ & 0.0001 & -0.4167 & 0.3819 & 0.2763 & 0.0003 & -0.0007 \\
$(12,1)$ & 0.0001 & 0.1377 & 0.2411 & 0.5684 & 0.0004 & -0.0018 \\
$(12,3)$ & -0.0005 & 0.0816 & 0.2603 & 0.7542 & 0.0005 & -0.0028 \\
$(24,1)$ & -0.0006 & 0.1885 & 0.1586 & 0.2358 & 0.0000 & 0.0058 \\
$(24,3)$ & -0.0015 & 0.2447 & 0.1706 & 0.1527 & 0.0000 & 0.0219 \\
$(36,1)$ & -0.0011 & 0.2481 & 0.1444 & 0.0871 & 0.0000 & 0.0184 \\
$(36,3)$ & -0.0023 & 0.3273 & 0.1982 & 0.1001 & 0.0008 & 0.0502 \\
$(48,1)$ & -0.0022 & 0.2786 & 0.1825 & 0.1283 & 0.0001 & 0.0327 \\
$(48,3)$ & -0.0034 & 0.3791 & 0.2467 & 0.1260 & 0.0126 & 0.0776 \\
\hline
\end{tabular}

${ }^{a}$ Estimated standard errors for the estimates of $\beta_{\mathrm{m}, \mathrm{n}}$. The standard errors are corrected using the Newey \& West (1987) method with lags = m-1.

Table 3b: The Mishkin model 1983:1 to 1992:9

\begin{tabular}{ccccccc}
\hline & & \multicolumn{5}{c}{$\mathrm{p}$-values for } \\
$(\mathrm{m}, \mathrm{n})$ & $\alpha_{\mathrm{m}, \mathrm{n}}$ & $\beta_{\mathrm{m}, \mathrm{n}}$ & $\mathrm{s}\left(\beta_{\mathrm{m}, \mathrm{n}}\right)^{\mathrm{a}}$ & $\beta_{\mathrm{m}, \mathrm{n}}=0$ & $\beta_{\mathrm{m}, \mathrm{n}}=1$ & Adj. $\mathrm{R}^{2}$ \\
$(3,1)$ & 0.0001 & -0.6212 & 0.4665 & 0.1858 & 0.0007 & -0.0012 \\
$(12,1)$ & 0.0009 & 0.0576 & 0.3234 & 0.8590 & 0.0043 & -0.0089 \\
$(12,3)$ & -0.0005 & 0.0079 & 0.4055 & 0.9845 & 0.0161 & -0.0093 \\
$(24,1)$ & 0.0002 & 0.2357 & 0.1843 & 0.2037 & 0.0001 & 0.0054 \\
$(24,3)$ & -0.0017 & 0.3082 & 0.2121 & 0.1493 & 0.0015 & 0.0195 \\
$(36,1)$ & -0.0003 & 0.3789 & 0.1837 & 0.0416 & 0.0010 & 0.0350 \\
$(36,3)$ & -0.0024 & 0.4985 & 0.2564 & 0.0545 & 0.0531 & 0.0711 \\
$(48,1)$ & -0.0007 & 0.4713 & 0.2343 & 0.0468 & 0.0261 & 0.0648 \\
$(48,3)$ & -0.0029 & 0.6353 & 0.3136 & 0.0453 & 0.2475 & 0.1256 \\
\hline
\end{tabular}

${ }^{\mathrm{a}}$ Estimated standard errors for the estimates of $\beta_{\mathrm{m}, \mathrm{n}}$. The standard errors are corrected using the Newey \& West (1987) method with lags = m-1.

Table 3c: The Mishkin model 1992:10 to 2004:10

\begin{tabular}{ccccccc}
\hline & & \multicolumn{5}{c}{$\mathrm{p}$-values for } \\
$(\mathrm{m}, \mathrm{n})$ & $\alpha_{\mathrm{m}, \mathrm{n}}$ & $\beta_{\mathrm{m}, \mathrm{n}}$ & $\mathrm{s}\left(\beta_{\mathrm{m}, \mathrm{n}}\right)^{\mathrm{a}}$ & $\beta_{\mathrm{m}, \mathrm{n}}=0$ & $\beta_{\mathrm{m}, \mathrm{n}}=1$ & Adj. $\mathrm{R}^{2}$ \\
$(3,1)$ & -0.0002 & 0.0973 & 0.7254 & 0.8935 & 0.2155 & -0.0075 \\
$(12,1)$ & -0.0010 & 0.3009 & 0.1834 & 0.1034 & 0.0002 & 0.0014 \\
$(12,3)$ & -0.0007 & 0.2438 & 0.1559 & 0.1205 & 0.0000 & 0.0125 \\
$(24,1)$ & -0.0009 & 0.1477 & 0.0807 & 0.0698 & 0.0000 & -0.0033 \\
$(24,3)$ & -0.0007 & 0.1392 & 0.0625 & 0.0281 & 0.0000 & 0.0096 \\
$(36,1)$ & -0.0005 & 0.0777 & 0.0557 & 0.1661 & 0.0000 & -0.0077 \\
$(36,3)$ & -0.0004 & 0.0682 & 0.0476 & 0.1554 & 0.0000 & -0.0030 \\
$(48,1)$ & -0.0016 & 0.0664 & 0.0390 & 0.0923 & 0.0000 & -0.0081 \\
$(48,3)$ & -0.0009 & 0.0315 & 0.0368 & 0.3935 & 0.0000 & -0.0089 \\
\hline
\end{tabular}

${ }^{a}$ Estimated standard errors for the estimates of $\beta_{\mathrm{m}, \mathrm{n}}$. The standard errors are corrected using the Newey \& West (1987) method with lags = m-1. 
the $\beta_{m, n}$ coefficients are found to be significantly different from 0 for 4 and 3 spreads, respectively. Notably, the estimates of the $\beta_{m, n}$ coefficients for the $(36, \mathrm{n})$ and $(48, \mathrm{n})$ spreads in the $1983: 1$ to $1992: 9$ period are relatively high ranging between 0.38 and 0.64 - and statistically significant.

The results of GIV estimation of the extended Mishkin model with the 1month real interest rate serving as the approximation to the slope of the term structure of expected real interest rates and inflation risk premiums are shown in table 4a-c. For the 1983:1 to 2004:10 period the extended Mishkin model is not supported for any spread. ${ }^{16}$ However, the approximation to the time-varying slope of the term structure of expected real interest rates and the inflation risk premiums is found to be significant and the term structure of interest rates is found to contain information about future inflation for the $(24,1),(36,1)$, $(36,3),(48,1)$ and $(48,3)$ spreads. The estimates of the $\beta_{m, n}$ coefficients for these spreads are relatively high - ranging between 0.33 and 0.66 . For the 1983:1 to 1992:9 period the extended Mishkin model is supported for the $(12,1),(24,1)$, $(36,1),(48,1)$ and $(48,3)$ spreads. In addition, the results indicate that the term structure of interest rates also contains information about future inflation for the $(36,3)$ spread. All the estimates of the $\beta_{m, n}$ coefficients - apart from the $(12,3),(24,3)$ and $(36,3)$ spreads - are high - ranging between 0.73 and 0.99 . For the 1992:10 to 2004:10 period the results are quite similar to the results for the 1983:1 to 2004:10 period. However, for the 1992:10 to 2004:10 period the term structure of interest rates seems to contain information about future inflation for all spreads except the $(3,1)$ and $(12,3)$ spreads.

Table 4a: The extended Mishkin model $(\mathrm{j}=1)$ 1983:1 to 2004:10

\begin{tabular}{ccccccccc}
\hline & & \multicolumn{1}{c}{$\mathrm{p}$-values for } \\
$(\mathrm{m}, \mathrm{n})$ & $\alpha_{\mathrm{m}, \mathrm{n}}$ & $\beta_{\mathrm{m}, \mathrm{n}}$ & $\mathrm{s}\left(\beta_{\mathrm{m}, \mathrm{n}}\right)^{\mathrm{a}}$ & $\gamma_{\mathrm{m}, \mathrm{n}}$ & $\beta_{\mathrm{m}, \mathrm{n}}=0$ & $\beta_{\mathrm{m}, \mathrm{n}}=1$ & $\gamma_{\mathrm{m}, \mathrm{n}}=0$ & Adj. $\mathrm{R}^{2}$ \\
$(3,1)$ & -0.0041 & 0.0877 & 0.5280 & 0.1214 & 0.8682 & 0.0853 & 0.1025 & 0.3139 \\
$(12,1)$ & -0.0065 & 0.2285 & 0.1782 & 0.1800 & 0.2011 & 0.0000 & 0.0028 & 0.4611 \\
$(12,3)$ & -0.0020 & 0.1160 & 0.2008 & 0.0618 & 0.5639 & 0.0000 & 0.1020 & 0.0304 \\
$(24,1)$ & -0.0086 & 0.3315 & 0.1459 & 0.2015 & 0.0240 & 0.0000 & 0.0125 & 0.4810 \\
$(24,3)$ & -0.0029 & 0.2426 & 0.1605 & 0.0616 & 0.1320 & 0.0000 & 0.1810 & 0.0496 \\
$(36,1)$ & -0.0197 & 0.5516 & 0.1637 & 0.4330 & 0.0009 & 0.0067 & 0.0001 & 0.4938 \\
$(36,3)$ & -0.0063 & 0.3524 & 0.1767 & 0.1307 & 0.0474 & 0.0003 & 0.0071 & 0.0758 \\
$(48,1)$ & -0.0235 & 0.6637 & 0.1528 & 0.4775 & 0.0000 & 0.0288 & 0.0002 & 0.4960 \\
$(48,3)$ & -0.0107 & 0.4811 & 0.1786 & 0.1681 & 0.0076 & 0.0041 & 0.0396 & 0.1181 \\
\hline
\end{tabular}

${ }^{a}$ Estimated standard errors for the estimates of $\beta_{\mathrm{m}, \mathrm{n}}$. The standard errors are corrected using the Newey \& West (1987) method with lags $=\mathrm{m}-1$.

\footnotetext{
${ }^{16}$ The extended Mishkin model is in the following said to be supported by the data if the null hypotheses $\beta_{m, n}=0$ and $\gamma_{m, n}=0$ are rejected and the null hypothesis $\beta_{m, n}=1$ is not rejected.
} 
Table 4b: The extended Mishkin model $(\mathrm{j}=1)$ 1983:1 to 1992:9

\begin{tabular}{ccccccccc}
\hline & \multicolumn{1}{c}{ p-values for } \\
$(\mathrm{m}, \mathrm{n})$ & $\alpha_{\mathrm{m}, \mathrm{n}}$ & $\beta_{\mathrm{m}, \mathrm{n}}$ & $\mathrm{s}\left(\beta_{\mathrm{m}, \mathrm{n}}\right)^{\mathrm{a}}$ & $\gamma_{\mathrm{m}, \mathrm{n}}$ & $\beta_{\mathrm{m}, \mathrm{n}}=0$ & $\beta_{\mathrm{m}, \mathrm{n}}=1$ & $\gamma_{\mathrm{m}, \mathrm{n}}=0$ & Adj. ${ }^{2}$ \\
$(3,1)$ & -0.0247 & 0.8768 & 0.6607 & 0.4824 & 0.1873 & 0.8524 & 0.0019 & 0.3268 \\
$(12,1)$ & -0.0411 & 0.8228 & 0.3573 & 0.7247 & 0.0232 & 0.6209 & 0.0000 & 0.5597 \\
$(12,3)$ & -0.0050 & 0.2208 & 0.3382 & 0.0927 & 0.5153 & 0.0232 & 0.2402 & 0.0291 \\
$(24,1)$ & -0.0405 & 0.8374 & 0.2238 & 0.6861 & 0.0003 & 0.4692 & 0.0000 & 0.4794 \\
$(24,3)$ & -0.0060 & 0.3422 & 0.2642 & 0.0849 & 0.1980 & 0.0143 & 0.4713 & 0.0419 \\
$(36,1)$ & -0.0405 & 0.8808 & 0.2210 & 0.7092 & 0.0001 & 0.5908 & 0.0000 & 0.4622 \\
$(36,3)$ & -0.0097 & 0.4920 & 0.2211 & 0.1294 & 0.0282 & 0.0236 & 0.1971 & 0.1005 \\
$(48,1)$ & -0.0482 & 0.9906 & 0.2103 & 0.8408 & 0.0000 & 0.9644 & 0.0000 & 0.5258 \\
$(48,3)$ & -0.0191 & 0.7270 & 0.1682 & 0.2684 & 0.0000 & 0.1076 & 0.0001 & 0.1813 \\
\hline
\end{tabular}

${ }^{a}$ Estimated standard errors for the estimates of $\beta_{\mathrm{m}, \mathrm{n}}$. The standard errors are corrected using the Newey \& West (1987) method with lags $=\mathrm{m}-1$.

Table 4c: The extended Mishkin model $(j=1)$ 1992:10 to 2004:10

\begin{tabular}{ccccccccc}
\hline & & \multicolumn{8}{c}{$\mathrm{p}$-values for } \\
$(\mathrm{m}, \mathrm{n})$ & $\alpha_{\mathrm{m}, \mathrm{n}}$ & $\beta_{\mathrm{m}, \mathrm{n}}$ & $\mathrm{s}\left(\beta_{\mathrm{m}, \mathrm{n}}\right)^{\mathrm{a}}$ & $\gamma_{\mathrm{m}, \mathrm{n}}$ & $\beta_{\mathrm{m}, \mathrm{n}}=0$ & $\beta_{\mathrm{m}, \mathrm{n}}=1$ & $\gamma_{\mathrm{m}, \mathrm{n}}=0$ & Adj. $\mathrm{R}^{2}$ \\
$(3,1)$ & -0.0008 & 0.0273 & 0.7302 & 0.0175 & 0.9703 & 0.1851 & 0.8912 & 0.5233 \\
$(12,1)$ & -0.0057 & 0.3628 & 0.1656 & 0.1575 & 0.0303 & 0.0002 & 0.0472 & 0.5855 \\
$(12,3)$ & -0.0017 & 0.2165 & 0.1445 & 0.0288 & 0.1365 & 0.0000 & 0.4369 & 0.0668 \\
$(24,1)$ & -0.0241 & 0.4376 & 0.1216 & 0.6863 & 0.0005 & 0.0000 & 0.0000 & 0.7777 \\
$(24,3)$ & -0.0022 & 0.1709 & 0.0624 & 0.0383 & 0.0072 & 0.0000 & 0.3709 & 0.0751 \\
$(36,1)$ & -0.0406 & 0.5002 & 0.1172 & 1.1497 & 0.0000 & 0.0000 & 0.0000 & 0.8688 \\
$(36,3)$ & -0.0187 & 0.3027 & 0.0878 & 0.5224 & 0.0008 & 0.0000 & 0.0000 & 0.1040 \\
$(48,1)$ & -0.0399 & 0.4865 & 0.0520 & 1.0786 & 0.0000 & 0.0000 & 0.0000 & 0.8319 \\
$(48,3)$ & -0.0224 & 0.2871 & 0.0453 & 0.5993 & 0.0000 & 0.0000 & 0.0000 & 0.0632 \\
\hline
\end{tabular}

${ }^{a}$ Estimated standard errors for the estimates of $\beta_{\mathrm{m}, \mathrm{n}}$. The standard errors are corrected using the Newey \& West (1987) method with lags $=\mathrm{m}-1$.

The results of GIV estimation of the extended Mishkin model with the 3month real interest rate serving as the approximation to the slope of the term structure of expected real interest rates and inflation risk premiums are shown in table 5a-c. For the 1983:1 to 2004:10 period the extended Mishkin model only seems to hold for the $(36,3)$ and $(48,3)$ spreads. For the $(36,1)$ and $(48,1)$ spreads, however, the $\beta_{m, n}=0$ hypothesis is rejected and the $\beta_{m, n}=1$ hypothesis is not rejected, i.e. the data also provide some support the extended Mishkin model in this case. Compared to the results for the standard Mishkin model, the estimates of the $\beta_{m, n}$ coefficients for the $(36, \mathrm{n})$ and $(48, \mathrm{n})$ spreads in the extended model are more than twice as large and the estimates of the $\beta_{m, n}$ coefficients for the $(24, \mathrm{n})$ spreads are also higher. For the 1983:1 to 1992:9 period, the extended Mishkin model is supported for the $(12,3),(24,3),(36,3)$, $(48,1)$ and $(48,3)$ spreads. For the $(24,1)$ and $(36,1)$ spreads, the $\beta_{m, n}=0$ hypothesis is rejected and the $\beta_{m, n}=1$ hypothesis is not rejected, i.e. the data provide some support for the extended Mishkin model for these spreads. For 
the 1992:10 to 2004:10 period, the extended Mishkin model does not hold for any spread. However, for all spreads except the $(3,1),(24,1)$ and $(36,1)$ spreads, the $\beta_{m, n}=0$ hypothesis is rejected, which indicates that the term structure of interest rates contains some information about future inflation. In addition, the approximation to the slope of the term structure of expected real interest rates and inflation risk premiums is significant for the $(24,3),(36, \mathrm{n})$ and $(48, \mathrm{n})$ spreads.

Table 5a: The extended Mishkin model ( $\mathrm{j}=3$ ) 1983:1 to 2004:10

\begin{tabular}{ccccccccc}
\hline & \multicolumn{1}{c}{$\mathrm{c}$-values for } \\
$(\mathrm{m}, \mathrm{n})$ & $\alpha_{\mathrm{m}, \mathrm{n}}$ & $\beta_{\mathrm{m}, \mathrm{n}}$ & $\mathrm{s}\left(\beta_{\mathrm{m}, \mathrm{n}}\right)^{\mathrm{a}}$ & $\gamma_{\mathrm{m}, \mathrm{n}}$ & $\beta_{\mathrm{m}, \mathrm{n}}=0$ & $\beta_{\mathrm{m}, \mathrm{n}}=1$ & $\gamma_{\mathrm{m}, \mathrm{n}}=0$ & Adj. $\mathrm{R}^{2}$ \\
$(3,1)$ & -0.0036 & 0.0170 & 0.6480 & 0.0982 & 0.9791 & 0.1305 & 0.4234 & 0.0077 \\
$(12,1)$ & -0.0098 & 0.4754 & 0.3124 & 0.2252 & 0.1294 & 0.0944 & 0.1326 & 0.0253 \\
$(12,3)$ & -0.0007 & -0.0521 & 0.2755 & 0.0225 & 0.8502 & 0.0002 & 0.7777 & 0.0939 \\
$(24,1)$ & -0.0147 & 0.5486 & 0.4102 & 0.2919 & 0.1824 & 0.2723 & 0.2973 & 0.0400 \\
$(24,3)$ & -0.0085 & 0.3429 & 0.1798 & 0.1943 & 0.0578 & 0.0003 & 0.1533 & 0.2408 \\
$(36,1)$ & -0.0365 & 0.8886 & 0.4585 & 0.7604 & 0.0539 & 0.8082 & 0.1301 & 0.0577 \\
$(36,3)$ & -0.0313 & 0.7031 & 0.3383 & 0.7322 & 0.0389 & 0.3813 & 0.0005 & 0.2665 \\
$(48,1)$ & -0.0357 & 0.8655 & 0.4637 & 0.6748 & 0.0634 & 0.7722 & 0.2542 & 0.1029 \\
$(48,3)$ & -0.0378 & 0.8238 & 0.2897 & 0.8062 & 0.0049 & 0.5437 & 0.0000 & 0.3479 \\
\hline
\end{tabular}

${ }^{a}$ Estimated standard errors for the estimates of $\beta_{\mathrm{m}, \mathrm{n}}$. The standard errors are corrected using the Newey \& West (1987) method with lags $=\mathrm{m}-1$.

Table 5b: The extended Mishkin model $(\mathrm{j}=3$ ) 1983:1 to 1992:9

\begin{tabular}{ccccccccc}
\hline & \multicolumn{1}{c}{ p-values for } \\
$(\mathrm{m}, \mathrm{n})$ & $\alpha_{\mathrm{m}, \mathrm{n}}$ & $\beta_{\mathrm{m}, \mathrm{n}}$ & $\mathrm{s}\left(\beta_{\mathrm{m}, \mathrm{n}}\right)^{\mathrm{a}}$ & $\gamma_{\mathrm{m}, \mathrm{n}}$ & $\beta_{\mathrm{m}, \mathrm{n}}=0$ & $\beta_{\mathrm{m}, \mathrm{n}}=1$ & $\gamma_{\mathrm{m}, \mathrm{n}}=0$ & Adj. $\mathrm{R}^{2}$ \\
$(3,1)$ & 0.0335 & -1.5746 & 1.0521 & -0.6317 & 0.1375 & 0.0160 & 0.2049 & 0.1016 \\
$(12,1)$ & -0.0577 & 1.3040 & 1.1427 & 1.0445 & 0.2564 & 0.7907 & 0.2071 & 0.0067 \\
$(12,3)$ & -0.0369 & 0.8492 & 0.4180 & 0.6177 & 0.0447 & 0.7191 & 0.0052 & 0.3830 \\
$(24,1)$ & -0.0568 & 0.9447 & 0.4560 & 1.1829 & 0.0407 & 0.9037 & 0.1153 & 0.0227 \\
$(24,3)$ & -0.0501 & 1.1466 & 0.2656 & 0.8307 & 0.0000 & 0.5820 & 0.0000 & 0.3480 \\
$(36,1)$ & -0.0691 & 1.2393 & 0.2627 & 1.4776 & 0.0000 & 0.3643 & 0.1040 & 0.0613 \\
$(36,3)$ & -0.0603 & 1.0560 & 0.2005 & 1.0383 & 0.0000 & 0.7804 & 0.0000 & 0.3820 \\
$(48,1)$ & -0.0649 & 1.4974 & 0.3045 & 1.4289 & 0.0000 & 0.1053 & 0.0831 & 0.1295 \\
$(48,3)$ & -0.0587 & 1.2343 & 0.2167 & 1.0500 & 0.0000 & 0.2819 & 0.0000 & 0.4811 \\
\hline
\end{tabular}

${ }^{a}$ Estimated standard errors for the estimates of $\beta_{\mathrm{m}, \mathrm{n}}$. The standard errors are corrected using the Newey \& West (1987) method with lags $=\mathrm{m}-1$. 
Table 5c: The extended Mishkin model $(\mathrm{j}=3)$ 1992:10 to 2004:10

\begin{tabular}{ccccccccc}
\hline & \multicolumn{1}{c}{ p-values for } \\
$(\mathrm{m}, \mathrm{n})$ & $\alpha_{\mathrm{m}, \mathrm{n}}$ & $\beta_{\mathrm{m}, \mathrm{n}}$ & $\mathrm{s}\left(\beta_{\mathrm{m}, \mathrm{n}}\right)^{\mathrm{a}}$ & $\gamma_{\mathrm{m}, \mathrm{n}}$ & $\beta_{\mathrm{m}, \mathrm{n}}=0$ & $\beta_{\mathrm{m}, \mathrm{n}}=1$ & $\gamma_{\mathrm{m}, \mathrm{n}}=0$ & Adj. $\mathrm{R}^{2}$ \\
$(3,1)$ & 0.0008 & -0.0706 & 0.8325 & -0.0343 & 0.9326 & 0.2007 & 0.7776 & -0.0140 \\
$(12,1)$ & -0.0010 & 0.5055 & 0.2625 & -0.0162 & 0.0565 & 0.0620 & 0.9277 & -0.0101 \\
$(12,3)$ & -0.0008 & 0.3631 & 0.1870 & -0.0170 & 0.0545 & 0.0009 & 0.8699 & -0.0122 \\
$(24,1)$ & -0.0264 & 0.4805 & 0.3569 & 0.7558 & 0.1810 & 0.1483 & 0.3149 & 0.0588 \\
$(24,3)$ & -0.0140 & 0.3576 & 0.1095 & 0.3772 & 0.0015 & 0.0000 & 0.0368 & 0.4032 \\
$(36,1)$ & -0.0487 & 0.4805 & 0.3953 & 1.3694 & 0.2270 & 0.1919 & 0.0053 & 0.0608 \\
$(36,3)$ & -0.0277 & 0.2983 & 0.1380 & 0.7583 & 0.0331 & 0.0000 & 0.0000 & 0.4959 \\
$(48,1)$ & -0.0534 & 0.5399 & 0.2335 & 1.3915 & 0.0232 & 0.0520 & 0.0124 & 0.0499 \\
$(48,3)$ & -0.0259 & 0.3087 & 0.0585 & 0.7179 & 0.0000 & 0.0000 & 0.0000 & 0.4155 \\
\hline
\end{tabular}

${ }^{a}$ Estimated standard errors for the estimates of $\beta_{\mathrm{m}, \mathrm{n}}$. The standard errors are corrected using the Newey \& West (1987) method with lags $=\mathrm{m}-1$.

For all periods the extended Mishkin model thus indicates that the term structure of interest rates contains more information about future inflation than the standard Mishkin model does. For the 1983:1 to 1992:9 period, i.e. the period prior to the inflation targeting monetary regime in the UK, the results also indicate that the extended Mishkin model holds for the $(36, \mathrm{n})$ and $(48, \mathrm{n})$ spreads, i.e. the extended Mishkin model is clearly supported when the slope along the entire term structure is used. ${ }^{17}$ Interestingly, in the 1983:1 to 1992:9 period, the extended Mishkin model is also supported for the $(12,1)$ and $(24,1)$ spreads when the 1-month real interest rate is used as an approximation to the time-varying slope of the term structure of expected real interest rates and inflation risk premiums. Likewise, the extended Mishkin model is supported for the $(12,3)$ and $(24,3)$ spreads in the $1983: 1$ to $1992: 9$ period when the 3 -month real interest rate is used as an approximation to the time-varying slope of the term structure of expected real interest rates and inflation risk premiums.

\section{Concluding remarks}

In this paper an extended version of the Mishkin model (2) has been proposed and tested. The extended Mishkin model (8) is derived from the Fisher equation including a time-varying inflation risk premium and a time-varying expected real interest rate. A single-factor representation of the sum of the expected real interest rate and the inflation risk premium is suggested, and based on the assumptions of rational expectations, ex post real interest rates for different maturities are used as an approximation to the expected real interest rate plus the inflation risk premium term in the extended Mishkin model. The empirical results show that the term structure of interest rates contains much more information about future inflation than is the case if the misspecified standard

\footnotetext{
${ }^{17}$ Interestingly, this result is much like the results obtained by Frankel \& Lown (1994) using a very different model.
} 
Mishkin model is examined. Interestingly, the data provide strong support for the extended model in the pre-inflation targeting period 1983:1 to 1992:9 in the UK when the slope along the entire term structure is used.

\section{References}

Anderson, N. \& Sleath, J. (2001), New estimates of the UK real and nominal yield curves. Bank of England Working Paper no. 126.

Bank of England (2002), Notes on the Bank of England UK yield curves. Note.

Benninga, S. \& Protopapadakis, A. (1983), 'Real and nominal interest rates under uncertainty: The Fisher theorem and the term structure', Journal of Political Economy 91(5), 856-867.

Breedon, F. J. \& Chadha, J. S. (1997), The information content of the inflation term structure. Bank of England Working Paper no. 75.

Browne, F. \& Manasse, P. (1990), 'The information content of the term structure of interest rates: Theory and evidence', OECD Economic Studies 14, 5986.

Cochrane, J. H. (2001), Asset Pricing, Princeton University Press, Princeton, New Jersey.

Cox, J. C., Ingersoll, J. E. \& Ross, S. A. (1985), 'A theory of the term structure of interest rates', Econometrica 53(2), 385 - 407.

Davidson, R. \& MacKinnon, J. G. (1993), Estimation and Inference in Econometrics, Oxford University Press, New York.

Day, J. \& Lange, R. (1997), The structure of interest rates in Canada: Information content about medium-term inflation. Bank of Canada Working Paper no. 97-10.

Evans, M. \& Wachtel, P. (1992), 'Interpreting the movements in short-term interest rates', Journal of Business 65(3), 395-429.

Fama, E. F. (1990), 'Term-structure forecasts of interest rates, inflation, and real returns', Journal of Monetary Economics 25(1), 59-76.

Frankel, J. A. \& Lown, C. S. (1994), 'An indicator of future inflation extracted from the steepness of the interest rate yield curve along its entire length', Quarterly Journal of Economics 109(2), 517-530.

Hansen, L. P. \& Singleton, K. J. (1982), 'Generalized instrumental variables estimation of nonlinear rational expectations models', Econometrica 50(5), 1269-1286. 
Heston, S. L. (1992), Testing continuous time models of the term structure of interest rates. Yale University, Working Paper Series F no. 29.

Jorion, P. \& Mishkin, F. (1991), 'A multicountry comparison of term-structure forecasts at long horizons', Journal of Financial Economics 29(1), 59-80.

Koedijk, K. G. \& Kool, C. J. M. (1995), 'Future inflation and the information in international term structures', Empirical Economics 20(2), 217-242.

MacKinnon, J. (1991), Critical values for cointegration tests, in R. Engle \& C. Granger, eds, 'Long-Run Economic Relationships - Readings in Cointegration', Oxford University Press, New York, pp. 267-276.

Mishkin, F. S. (1990a), 'The information in the longer maturity term structure about future inflation', Quarterly Journal of Economics 105(3), 815-828.

Mishkin, F. S. (1990b), 'What does the term structure tell us about future inflation?', Journal of Monetary Economics 25(1), 77-95.

Mishkin, F. S. (1991), 'A multi-country study of the information in the shorter maturity term structure about future inflation', Journal of International Money and Finance 10(1), 2-22.

Newey, W. \& West, K. (1987), 'A simple, positive definite, heteroscedasticity and autocorrelation consistent covariance matrix', Econometrica $\mathbf{5 5}(3), 703-708$.

Office for National Statistics (1998), The Retail Prices Index Technical Manual.

Schich, S. T. (2000), What the yield curves say about inflation: Does it change over time? OECD Economic Department Working Paper no. 227.

Tzavalis, E. \& Wickens, M. R. W. (1997), 'Explaining the failures of the term spread models of the rational expectations hypothesis of the term structure', Journal of Money, Credit and Banking 29(3), 364-380. 